\title{
Comparison of gas test system based on the syringe with the reading pressure technique*
}

\author{
Z.Y. Duan, W.J. Yan, Y.M. Wu, J.A. Ye and J.X. Liu' \\ Institute of Dairy Science, Zhejiang University \\ Hangzhou 310029, P.R. China
}

(Received 7 June 2005; revised version 25 October 2005; accepted 6 January 2006)

\begin{abstract}
An investigation was conducted to compare the syringe gas test system with the reading pressure technique (RPT). A series of mixtures of neutral detergent fibre (NDF) and maize starch were incubated using both systems and the ratios (wt/wt) of maize starch in the mixtures were $0,10.0,20.0,25.0,33.3$, $50.0,55.6,62.5,71.4,83.3$ and $100 \%$. The gas production (GP) was recorded at $0,2,4,6,9,12,24$, 36,48 and $72 \mathrm{~h}$. There was no significant difference in potential GP between two systems (corrected to $200 \mathrm{mg}$ substrate basis) ( $\mathrm{P}>0.05$ ), while the GP at a short time of incubation were lower in the RPT system than in the syringe and the rate constant of GP was significantly higher in the syringe $(\mathrm{P}<0.05)$. However, a strong relationship was observed between the $24 \mathrm{~h} \mathrm{GP}$ values $\left(\mathrm{GP}_{24 \mathrm{~h}}\right)$ in the syringe system and the RPT, which was described by: $\mathrm{GP}_{24 \mathrm{~h}}$ for the syringe system $(\mathrm{ml})=1.2628 \times \mathrm{GP}_{24 \mathrm{~h}}$ for the RTP system $(\mathrm{ml})+6.2592\left(R^{2}=0.9784 ; \mathrm{P}<0.01 ; n=132\right)$. It is indicated that the $\mathrm{GP}_{24 \mathrm{~h}}$ in the two systems can be revised reciprocally and appropriate system could be chosen according to the research objectives and characteristics of both methods.
\end{abstract}

KEY WORDS: gas production in vitro, syringe system, RPT system

\section{INTRODUCTION}

The performance of ruminants is largely influenced by forage quality which includes the compositions of fermentation end products, digestibility, degradation rate, etc. (Minson, 1990). Because determination of the nutritional parameters in vivo is time-consuming, laborious, expensive, in poor animal welfare and unsuitable for large scale (Coelho et al., 1988; Carro et al., 1994), ruminant nutritionists have long focused on evaluation of the forage quality through reasonable methods,

\footnotetext{
* Partly supported by the National Natural Science Foundation of China, No. 30325033, and TransCentury Training Programme Foundation for the Talents by Ministry of Education of China

${ }^{1}$ Corresponding author: e-mail: liujx@zju.edu.cn
} 
such as in situ (Mehrez and Ørskov, 1977) and in vitro techniques (Menke et al., 1979; Theodorou et al., 1994).

The current approaches of in vitro gas production (GP) for feedstuff evaluation could be classified into two main types. Menke et al. (1979) described an in vitro system, in which gas produced from fermentation of a substrate was used to estimate digestibility and metabolizable energy content. Using their system, a high relationship may be established between the in vitro GP and in vivo digestibility. During the last two decades, the in vitro gas test technique has been widely used to evaluate the nutritional quality of forage. A simple gas production method using a pressure transducer (reading pressure technique, RPT) was developed by Theodorou et al. (1994) and modified by Mauricio et al. (1999). In their system, a pressure transducer interfaced with a PC was used to measure the accumulated gas pressure values in the sealed fermentation bottles. According to the empirical gas law of Boyle and Gay-Lussac (PV = nRT, where: $\mathrm{P}=$ pressure of gas, atm; $\mathrm{V}=$ volume of gas, $1 ; \mathrm{n}=$ number of moles of gas; $\mathrm{R}$ $=$ the molar gas constant at $0{ }^{\circ} \mathrm{C}$ and $760 \mathrm{~mm} \mathrm{Hg} ; \mathrm{T}=$ temperature, ${ }^{\circ} \mathrm{K}$ ), the $\mathrm{GP}$ values were then calculated from the pressure data saved in PC.

However, the results may be different when the same samples were incubated in the two systems with different procedures, i.e. the formulations of the buffer fluid, the ratio of rumen fluid to the buffer, etc. Therefore, the data could not be compared directly and the formulations established based on syringe system could not be used in RPT. The objectives of the present study were: 1 . to directly compare the results when the same samples were fermented in the two systems, 2 . to study the correlations between the systems and 3. to analyse the pros and cons of the two systems in order to choose the appropriate method according to the objectives of study.

\section{MATERIAL AND METHODS}

\section{Samples preparation}

Maize starch was bought from Hangzhou Food Co., Ltd. (China). Neutral detergent fibre (NDF) was isolated from two roughages, rice straw and Chinese wild rye, respectively. The methods proposed by Robertson and Van Soest (1981) and Van Soest et al. (1991) were used for the isolation of the roughage NDF. After the NDF was insolated, it was immersed in ammonium sulphate $\left(\left(\mathrm{NH}_{4}\right)_{2} \mathrm{SO}_{4}\right)$ solution $(1 \mathrm{M})$ at $39^{\circ} \mathrm{C}$ overnight in order to remove detergent ionic traces from samples (Schofield and Pell, 1995). Then, samples were washed again in hot water and ethanol, filtered in crucibles with porous discs and oven-dried at $50^{\circ} \mathrm{C}$. The NDF contents were 95.4 and $99.1 \%$ DM in the NDF preparations from rice straw and Chinese wild rye, respectively. The hemicellulose, cellulose, lignin and crude ash contents were 24.6, 60.0, 9.0 and 6.4\% DM in the rice straw NDF preparation (low quality), and were 39.9, 46.9, 11.3 and $1.9 \%$ in the Chinese wild rye NDF (high quality), respectively. 
The NDFs were mixed with maize starch, and the ratios (wt/wt) of maize starch in the mixtures were $0,10.0,20.0,25.0,33.3,50.0,55.6,62.5,71.4,83.3$ and $100 \%$.

\section{Gas production test}

The samples mixed at the above ratios were incubated in the syringe system described by Menke et al. (1988) and in the RPT developed by Mauricio et al. (1999), respectively.

Rumen fluid was collected from three rumen cannulated sheep before the morning feeding. The sheep were offered $1000 \mathrm{~g}$ DM per day of compound feed, containing 30\% concentrates and $70 \%$ hay. Rumen fluid from the three sheep was combined, filtered through four layer of cheesecloth, and stored in a warm insulated flask filled with $\mathrm{CO}_{2}$.

In the syringe system, the rumen fluid was mixed with an anaerobic buffer/mineral solutions (1:2, v/v) as described by Menke et al. (1988). Samples (200 mg, DM) were incubated in $100 \mathrm{ml}$ syringes filled with $30 \mathrm{ml}$ buffered rumen fluid in a shaking water bath at $39^{\circ} \mathrm{C}$. In the RPT, the anaerobic buffer/mineral solution described by Mauricio et al. (1999) was used and the ratio of rumen fluid to buffer/mineral solution was 1:9 (v/v). Samples (1000 mg, DM) immersed in $100 \mathrm{ml}$ buffered rumen fluid in 160 $\mathrm{ml}$ fermentation bottles were incubated in an air bath incubator at $39^{\circ} \mathrm{C}$. A pressure transducer connected with PC was used to measure the accumulated head-space gas pressures in the fermentation bottles sealed with rubber lids by sticking a syringe needle into the bottles, and the data were directly entered into a spreadsheet. The GP values were converted from the gas pressures saved in the PC.

Two runs of incubation were carried out, with triplicate in each run. The gas production was recorded at $0,2,4,6,9,12,24,36,48$ and $72 \mathrm{~h}$.

\section{Computation of data and statistical analysis}

The gas production in the RPT was corrected to $200 \mathrm{mg}$ substrate (DM) according to the linear relationship between quantity of substrate and gas production (Theodorou et al., 1994). The following single pool exponential equation of McDonald (1981) was fitted to calculate the gas production parameters:

$$
\mathrm{GP}=a+b(1-\exp (-c \mathrm{t}))
$$

where, GP is the cumulative gas production at time t, and $a, b, c$ are the GP of soluble fraction, the GP of insoluble but fermentable fraction, and the rate constant of GP, respectively. The potential GP is given by $a+b$. The relationships between the GPs at $24 \mathrm{~h}$ of incubation $\left(\mathrm{GP}_{24 \mathrm{~h}}\right)$ from the two systems were examined in regression procedure (REG).

The $\mathrm{GP}_{24 \mathrm{~h}}$ values, potential GP and rate constant of GP from the two systems were compared by $\mathrm{T}$ test using the statistical software SAS (v6.12, 1996). Significance was declared when $\mathrm{P}<0.05$. 


\section{SYRINGE SYSTEM AND PRESSURE TECHNIQUE FOR FEED EVALUATION}

\section{RESULTS}

Gas production characteristics and digestion kinetics of fermentation

The cumulative gas production curves are presented in Figures 1 and 2 for some representative mixtures of maize starch with NDF extracted from Chinese wild rye and from rice straw, respectively. The $\mathrm{GP}_{24 \mathrm{~h}}$, potential GP $(a+b)$ and rate constant of GP $(c)$ for two mixture series are given in Tables 1 and 2.

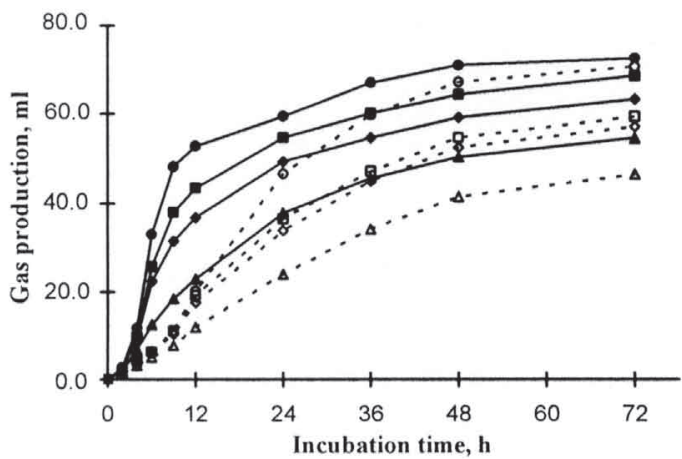

Figure 1. Gas production curves for some representative mixtures of maize starch and neutral detergent fibre extracted from Chinese wild rye when fermented using syringe $(-)$ and reading pressure technique $(\cdots \cdots)$. The maize starch contents of the mixtures were $25.0(-\boldsymbol{\leftarrow}, \cdots . \Delta), 50.0$ $(\neg-, \cdots \cdots), 62.5(-, \cdots \cdots)$ and $83.3 \%(-,, \cdots \odot)$, respectively

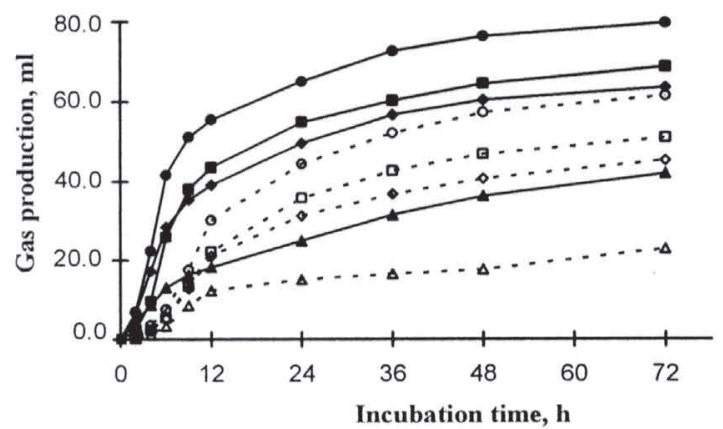

Figure 2. Gas production curves for some representative mixtures of maize starch and neutral detergent fibre extracted from Chinese wild rye when fermented using syringe $(-)$ and reading pressure technique $(\cdots \cdots)$. The maize starch contents of the mixtures were $25.0(-\leftarrow, \cdots \Delta), 50.0$ $(\neg, \cdots \ominus \cdots), 62.5(-\square, \cdots \cdots)$ and $83.3 \%(-\bullet, \cdots \cdots)$, respectively 
Table 1. Values of gas production (GP) at $24 \mathrm{~h}$ of incubation, potential GP and rate constant of GP for the mixtures of maize starch and neutral detergent fibre extracted from rice straw when incubated using syringe and reading pressure technique $(\mathrm{RPT})(\mathrm{n}=6)$

\begin{tabular}{|c|c|c|c|c|c|c|c|c|c|}
\hline \multirow{2}{*}{$\begin{array}{l}\text { Maize starch } \\
\text { Ratios, \% }\end{array}$} & \multicolumn{3}{|c|}{$\mathrm{GP}$ at $24 \mathrm{~h}, \mathrm{ml}$} & \multicolumn{3}{|c|}{ Potential GP, ml } & \multicolumn{3}{|c|}{ Rate of GP, $\% \mathrm{~h}^{-1}$} \\
\hline & Syringe & RPT & SEM & Syringe & RPT & SEM & Syringe & RPT & SEM \\
\hline 0.0 & 4.8 & 0.0 & 0.06 & 46.7 & 0.0 & 0.09 & 0.02 & 0.00 & 0.00 \\
\hline 11.1 & 12.4 & 5.0 & 0.28 & 49.2 & 37.8 & 0.15 & 0.75 & 0.01 & 0.02 \\
\hline 20.0 & 20.4 & 11.9 & 0.57 & 57.0 & 56.2 & 0.84 & 2.82 & 0.64 & 0.35 \\
\hline 25.0 & 23.7 & 15.1 & 0.54 & 53.6 & 52.8 & 1.85 & 3.95 & 1.00 & 0.54 \\
\hline 33.3 & 32.7 & 21.2 & 0.34 & 58.5 & 57.0 & 1.05 & 4.82 & 1.49 & 0.43 \\
\hline 50.0 & 43.8 & 31.3 & 0.28 & 63.5 & 61.7 & 0.95 & 8.58 & 1.97 & 0.87 \\
\hline 55.6 & 47.4 & 33.5 & 0.67 & 65.8 & 62.6 & 2.18 & 8.53 & 2.01 & 1.20 \\
\hline 62.5 & 53.1 & 35.8 & 0.28 & 71.4 & 64.7 & 2.02 & 9.02 & 2.82 & 1.35 \\
\hline 71.4 & 57.8 & 37.9 & 0.73 & 76.9 & 74.3 & 1.93 & 10.41 & 3.04 & 1.84 \\
\hline 83.3 & 65.2 & 44.3 & 1.37 & 79.7 & 74.5 & 0.54 & 10.47 & 3.17 & 1.33 \\
\hline 100.0 & 70.6 & 51.8 & 1.08 & 85.4 & 83.2 & 1.87 & 11.39 & 3.16 & 1.49 \\
\hline
\end{tabular}

Table 2. Values of gas production (GP) at $24 \mathrm{~h}$ of incubation, potential GP and rate constant of GP for the mixtures of maize starch and neutral detergent fibre extracted from Chinese wild rye when incubated using syringe and reading pressure technique (RPT) $(n=6)$

\begin{tabular}{|c|c|c|c|c|c|c|c|c|c|}
\hline \multirow{2}{*}{$\begin{array}{l}\text { Maize starch } \\
\text { Ratios, } \%\end{array}$} & \multicolumn{3}{|c|}{$\mathrm{GP}$ at $24 \mathrm{~h}, \mathrm{ml}$} & \multicolumn{3}{|c|}{ Potential GP, ml } & \multicolumn{3}{|c|}{ Rate of GP, $\% \mathrm{~h}^{-1}$} \\
\hline & Syringe & RPT & SEM & Syringe & RPT & SEM & Syringe & RPT & SEM \\
\hline 0.0 & 24.3 & 12.6 & 0.83 & 49.5 & 38.6 & 0.73 & 2.02 & 0.87 & 0.44 \\
\hline 11.1 & 31.1 & 21.4 & 0.62 & 51.8 & 49.8 & 1.21 & 2.97 & 1.35 & 0.57 \\
\hline 20.0 & 35.1 & 25.4 & 0.61 & 59.5 & 57.6 & 0.87 & 4.28 & 2.41 & 0.29 \\
\hline 25.0 & 36.6 & 26.0 & 0.54 & 59.3 & 58.0 & 0.54 & 4.66 & 2.75 & 0.15 \\
\hline 33.3 & 41.5 & 29.2 & 0.87 & 60.9 & 60.2 & 0.96 & 5.35 & 2.80 & 0.67 \\
\hline 50.0 & 49.5 & 33.9 & 1.45 & 67.7 & 66.0 & 1.25 & 7.48 & 3.20 & 0.54 \\
\hline 55.6 & 50.4 & 36.5 & 1.64 & 69.3 & 67.8 & 1.34 & 7.59 & 3.21 & 0.92 \\
\hline 62.5 & 55.0 & 40.4 & 1.34 & 69.9 & 69.0 & 1.05 & 8.63 & 3.27 & 1.24 \\
\hline 71.4 & 59.5 & 43.6 & 0.95 & 74.7 & 73.6 & 0.57 & 9.82 & 3.43 & 1.44 \\
\hline 83.3 & 61.3 & 46.6 & 0.26 & 78.4 & 75.3 & 0.87 & 10.89 & 3.75 & 1.08 \\
\hline 100.0 & 69.4 & 53.8 & 1.96 & 84.7 & 83.5 & 1.05 & 11.36 & 3.81 & 1.57 \\
\hline
\end{tabular}

The $\mathrm{GP}_{24 \mathrm{~h}}$ values obtained from the syringe system were significantly higher than that from RPT at the same incubating time $(\mathrm{P}<0.05)$, while the tendencies of the GP with incubating time were similar. When the substrates with low quality NDF (rice straw) were incubated, the differences between the GP values from the syringe and RPT system were higher than those when the mixtures consisted of high quality NDF from Chinese wild rye. In both systems, the potential GP and rate constant of GP increased with the increasing content of maize starch in the mixture. For most 
mixtures, there was no significant difference in potential GP between two systems $(\mathrm{P}>0.05)$, while the values in the RPT were much lower when maize starch content was lower $(\mathrm{P}<0.05)$. Low quality NDF was rarely fermented in the RTP, and the GP values for rice straw NDF were nearly $0 \mathrm{ml}$ at all times of incubation. The rate constant was significantly lower in the RPT than in the syringe system for all mixtures $(\mathrm{P}<0.05)$.

Correlations in the GP values between the systems

A high linear relationship existed between the $\mathrm{GP}_{24 \mathrm{~h}}$ values for the syringe $(Y)$ and the RPT system $(X)$ (Figure 3). Regression analysis of these relationships

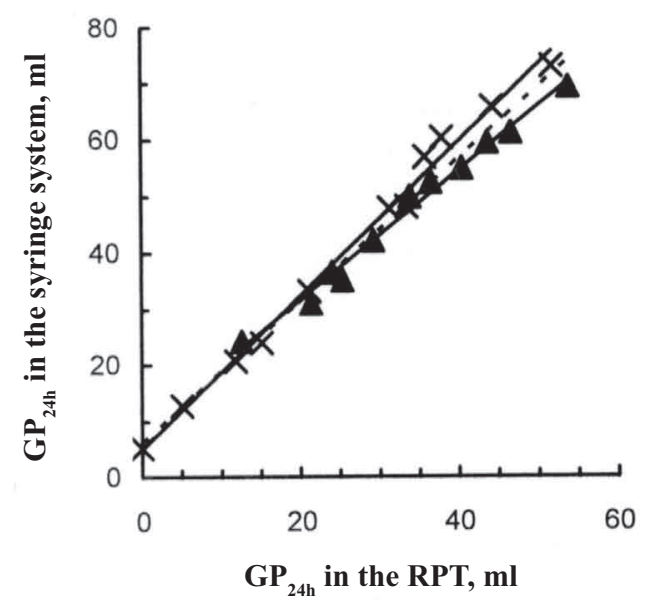

Figure 3. Relationships between the gas productions at $24 \mathrm{~h}$ of incubation $\left(\mathrm{GP}_{24 \mathrm{~h}}\right)$ in both systems. Real lines represent the relationships between the $\mathrm{GP}_{24 \mathrm{~h}}$ values from the mixtures of maize starch and neutral detergent fibre from Chinese wild rye $\left(\boldsymbol{\Lambda}, Y=1.3667 X+4.9893, R^{2}=0.9924, \mathrm{P}<0.01 ; n\right.$ $=66)$, and from rice straw $\left(\times, Y=1.1479 X+8.6512, R^{2}=0.9875, \mathrm{P}<0.01, n=66\right)$, when incubated using syringe and reading pressure technique (RPT). Dashed line represents the relationship between the $\mathrm{GP}_{24 \mathrm{~h}}$ values obtained from two systems for the pooled data of both series mixtures $\left(Y=1.2628 X+6.2592, R^{2}=0.9784, \mathrm{P}<0.01, n=132\right)$

resulted in equations 1 for rice straw NDF mixture and 2 for Chinese wild rye NDF mixture:

$$
\begin{array}{ll}
Y=1.3667 X+4.9893 & \left(R^{2}=0.9924 ; p<0.01 ; n=66\right) \\
Y=1.1479 X+8.6512 & \left(R^{2}=0.9875 ; p<0.01 ; n=66\right)
\end{array}
$$

Equation 3 gave the correlation for the data from two series of mixtures:

$$
Y=1.2628 X+6.2592 \quad\left(R^{2}=0.9784 ; p<0.01 ; n=132\right)
$$




\section{DISCUSSION}

\section{Gas production characteristics}

The slower rate constants of GP in the RPT system than in the syringe resulted in the lower gas values at a short time of incubation in the RPT. The GP was very low when low-quality substrate was incubated in RPT. This might be attributed to the ratio of rumen fluid to buffer medium in the culture media $(1: 9, \mathrm{v} / \mathrm{v})$. A lower content of rumen fluid will produce lower blanks, as the microbe in the culture may be not active enough. Hidayat et al. (1993) found increased rates of gas production from forages, in response to increased bacterial density. It has been showed that a buffered medium containing 20-25\% rumen fluid gave the best results (Hungate et al., 1955; Tilley and Terry, 1963; Pell and Schofield, 1993). However, the amount of added inoculum varies widely between different laboratories. In the syringe-based system, $10 \mathrm{ml}$ rumen fluid is added to $20 \mathrm{ml}$ medium, while $10 \mathrm{ml}$ rumen fluid is added to $90 \mathrm{ml}$ medium in RPT system. Thus, the microbe densities of the culture media are not the same, which may lead to different results in these two systems when the same samples are incubated. Further study is needed to investigate the effect of rumen fluid-to-buffer ratio on the gas values in both systems.

\section{Data conversion between the two systems}

Syringe method has been used for over two decades and has been standardized. Many available models and formulas have been established in this system. The organic matter digestibility and metabolizable energy content may be estimated from the GP (Menke et al., 1979; Menke and Steingass, 1988). However, little information is available on these parameters in RPT system.

Because of the difference in the $\mathrm{GP}_{24 \mathrm{~h}}$ for the same sample (Tables 1 and 2), the data from the two systems could not be compared and analysed directly. If the formulations from the syringe system are used for the RPT, the nutritional values of feeds may be underevaluated. In this study, high relationship was established between the $\mathrm{GP}_{24 \mathrm{~h}}$ values from two systems. Because two typical fibres (representation of low and high quality) and wide ratios of concentrate to roughage were used in the incubation, the relationship could be applicable to wide range of feedstuffs.

\section{Pros and cons of the systems}

The equipments of syringe method are simpler than those for the RPT. It needs no sensor transducer and PC, and the cumulative gas production is directly read at the position of the piston. However, the syringe is more expensive (about 50 USD each) than the serum bottle (about 2 USD each). Even including the pressure 
transducer and PC, the RPT is much cheaper than the syringe system. Due to the high initial cost for syringe method, the RPT is more appropriate for many laboratories, especially in the developing countries.

In the syringe system, the cumulative gas is read manually, the time taken to obtain each reading and the disadvantages that gas volume measurements have to be read and entered manually limit both the capacity and accuracy. For a kinetic analysis of feedstuff digestion, many timed readings are necessary. Compared to these, data can be obtained more quickly and at shorter intervals in RPT system, which are essential for the calculation of fermentation kinetics. Furthermore, the RPT is more sensitive than the syringe system when small gas volumes were measured, as the sensitivity of the RPT system may be adjusted based on the bottle size and the sensor range. In our group, $0.2 \mathrm{ml}$ of the accumulated gas volume change can be detected accurately when $160 \mathrm{ml}$ serum bottles are used, while the least accurate detection is $1 \mathrm{ml}$ of gas volume change in the syringe system.

Limited by the volume of the syringe, only small quantity of sample (200-500 $\mathrm{mg}$ ) may be incubated in the syringe method. Because most of animal feedstuffs are not homogeneous, sample problem is presented sometimes. If the sample is milled into too small size to resolve this problem, the fermentation in vitro may be much different from that in vivo. Furthermore, when the end products need to be analysed, the leftover substrate would be not adequate. In the RPT system, $500-1000 \mathrm{mg}$ of substrates could be incubated in one bottle, which may ensure the homogeneousness of sample and more end products could be obtained for analysis of fermentation parameters, such as microbial protein, particle bound cellulase activity, microbial populations, etc.

When the substrates are incubated, the fermentation products must be sampled and analysed sometimes, i.e. the gas, the fermentation liquid and solid products. In the syringe method, if fermentation products are required, syringes need to be sacrificed. Thus, one can only get the fermentation products at one time, while the fermentation products can be sampled continuously in the RPT system. The gas sample can be obtained from the rubber stopper at any times after the pressure has been recorded. When the fluid or digesta must be analysed, no more than 1-2 $\mathrm{ml}$ samples are needed and this quantity is inappreciable to the $100 \mathrm{ml}$ culture media. After fermentation products were sampled at required times, the bottles were filled with $\mathrm{CO}_{2}$ again, and further incubation could be continued.

\section{CONCLUSIONS}

In summary, the in vitro feed evaluation system based on gas production from either syringe or reading pressure technique has respective advantages, and could be chosen for use in practice depending on the purposes of research. The syringe 
system may be used to record the gas values at different times of incubation, and analysis of fermentation parameters may be conducted for the inoculants at the end point. If the continuous analyses of the fermented end products would be expected, the reading pressure technique is proposed. Depending on the initial cost, precise and convenience, the reading pressure technique may be suitable to many laboratories in the developing countries.

\section{REFERENCES}

Carro M.D., Lopez S., Gonzalez J.S., Ovejero F.J., 1994. Comparison of laboratory methods for predicting digestibility of hay in sheep. Small Ruminant Res. 14, 9-17

Coelho M., Hembry F.G., Barton F.E., Saxton A.M., 1988. A comparison of microbial, enzymatic, chemical and near-infrared reflectance spectroscopy method in forage evaluation. Anim. Feed Sci. Tech. 20,219-231

Hidayat Hillman K., Newbold C.J., Stewart C.S., 1993. The contributions of bacteria and protozoa to ruminal forage fermentation in vitro, as determined by microbial gas production. Anim. Feed Sci. Tech. 42, 193-208

Hungate R.E., Fletcher D.W., Dougherty R.W., Barrentine B.F., 1955. Microbial activity in the bovine rumen: its measurement and relation to bloat. Appl. Microbiol. 3, 161-173

Mauricio R.M., Mould F.L., Dhanoa M.S., Owen E., Channa K.S., Theodorou M.K., 1999. Semiautomated in vitro gas production technique for ruminant feedstuff evaluation. Anim. Feed Sci. Tech. 79, 321-330

McDonald I., 1981. A revised model for the estimation of protein degradability in the rumen. J. Agr. Sci. 96, $251-252$

Mehrez A.Z., Ørskov E.R., 1977. A study of the artificial fibre bag technique for determining the digestibility of feeds in the rumen. J. Agr. Sci. 88, 645-650

Menke K.H., Raab L., Salewski A., Steingass H., Fritz D., Schneider W., 1979. The estimation of the digestibility and metabolisable energy content of ruminant feeding stuffs from the gas production when they are incubated with rumen liquor. J. Agr. Sci. 93, 217-222

Menke K.H., Steingass H., 1988. Estimation of the energetic feed value obtained from chemical analysis and in vitro gas production using rumen fluid. Anim. Res. Develop. 28, 7-55

Minson D.J., 1990. Forage in Ruminant Nutrition. Academic Press, San Diego

Pell A.N., Schofield P., 1993. Computerized monitoring of gas production to measure forage digestion in vitro. J. Dairy Sci. 76, 1063-1073

Robertson J.B., Van Soest P.J., 1981. The detergent system of analysis. In: W.P.T. James, O. Theander (Editors). The Analysis of Dietary Fiber in Food. Marcel Dekker, NY, Basel

SAS Package, 1996. SAS/STAT User's Guide, Version 6.12. Cary, NC: SAS Institute Inc.

Schofield P., Pell A.N., 1995. Measurement and kinetics analysis of the neutral detergent-soluble carbohydrate fraction of legumes and grasses. J. Anim. Sci. 73, 1104-1115

Theodorou M.K., Williams B.A., Dhanoa M.S., McAllan A.B., 1994. A simple gas production method using a pressure transducer to determine the fermentation kinetics of ruminant feeds. Anim. Feed Sci. Tech. 48, 185-197

Tilley J.M.A., Terry R.A., 1963. A two stage technique for the in vitro digestion of forage crops. J. Brit. Grassl. Soc. 18, 104-111

Van Soest P.J., Robertson J.B., Lewis B.A., 1991. Methods for dietary fibre, neutral detergent fibre, and nonstarch polysaccharides in relation to animal nutrition. J. Dairy Sci. 74, 3583-3597 